\title{
MEDIA PEMBELAJARAN DESAIN WEB MENGGUNAKAN PHOTOSHOP CS6 DAN ADOBE DREAMWEAVER BERBASIS MULTIMEDIA
}

\author{
Ahmad Surahmat ${ }^{1}$, Sukarta Atmaja ${ }^{2}$ \\ Dosen Fakultas Ilmu Komputer, Universitas Banten Jaya \\ Jl. Syeh Nawawi Al-Bantani, Boru, Serang - Banten \\ Email: ahmadsurahmat@unbaja.ac.id ${ }^{1}$, sukartaatmaja@gmail.com ${ }^{1}$
}

\begin{abstract}
In designing a beautiful and attractive web, for ordinary people it certainly looks very difficult. So from that the advantage of learning to use learning media using multimedia is that people can see firsthand how and the steps? And the results of how they are made can be seen immediately. Compare this with a book that has a step by step guide, but people will feel confused because not a few books give results that are not in accordance with the method. Learning media that will be displayed in the form of a website display. With the help of Photoshop CS6 and Adobe Dreamweaver application we can make web display easier and also create websites without direct contact with the programming language. Multimedia-based learning aims to facilitate students in understanding each method of web design techniques. In this study discussed how to design web using Photoshop CS6 with the help of slice tool. Multimedia-based web design learning media uses three methods, namely web designing in Photoshop CS6, adding code with Adobe Dreamweaver, and making learning videos using Camtasia Studio 8, the learning videos produced can be seen with the .wav flv .swf format with CD quality, DVD. The results of this study were conducted to develop multimedia-based learning media so that the material delivered was easier to understand.
\end{abstract}

Keywords: Dreamweaver, Multimedia, Photoshop.

\section{PENDAHULUAN}

Perkembangan pendidikan di Indonesia kini semakin inovatif, di mana berbagai macam teknologi telah dikembangkan untuk meningkatkan mutu pendidikan. Untuk mencapai tujuan pembelajaran tersebut, dengan menerapkan pembelajaran yang berbasiskan multimedia. Dalam teknologi pembelajaran ini menggunakan teknologi informasi sebagai media utama yang didukung dengan berbagai macam aplikasi (software) untuk membuat sistem pembelajaran. Ada empat komponen yang mendukung sistem ini yaitu sistem operasi, software, hardware, dan internet.

Salah satu pemanfaatan multimedia dalam bidang pembelajaran adalah dengan membuat media belajar. Pembuatan media ini nantinya dikhususkan hanya 
pada penggunaan Photoshop untuk desain web sebagai obyek pembelajaran. Media pembelajaran yang akan ditampilkan dalam bentuk tampilan website.

Bagi kebanyakan orang yang belum pernah mengenal pembuatan desain web tentu akan terlihat sangat sulit. Apalagi bila desain web dengan menggunakan code atau tag HTML yang begitu banyak. Dengan bantuan aplikasi Photoshop, sekarang mendesain tampilan web menjadi lebih mudah dan cepat. Dengan bantuan aplikasi Adobe Dreamweaver kita dapat membuat situs web tanpa bersentuhan langsung dengan bahasa pemograman, cukup mengetahui dasar dasarnya saja, karena di dalam aplikasi ini sudah disediakan alat - alat otomatis. Bahkan tampilan yang dihasilkan dapat dilengkapi dengan berbagai macam background yang menarik.

Maka belajar mendesain web menggunakan multimedia akan lebih mudah untuk dipahami. Karena didukung dengan tampilan video yang mudah diikuti dan dipelajari. Dari hasil penelitian penggunaan Photoshop dengan Dreamweaver untuk desain web dengan menggunakan media belajar berbasis multimedia materi yang disampaikan dapat dipahami dengan baik. Adapun tujuan penelitian ini adalah untuk membuat media pembelajaran dengan menggunakan aplikasi Camtasia Studio.

\section{METODE PENELITIAN}

\section{Konsep Dasar Belajar}

Lingkungan belajar multimedia interaktif dapat dikategorikan dalam tiga jenis yakni lingkungan belajar preskriptif, demokratis dan sibernetik. Lingkungan preskriptif menekankan bahwa prestasi belajar merupakan pencapaian dari tujuan-tujuan belajar yang ditetapkan secara eksternal. Interaksi belajar terjadi antara siswa dengan bahan-bahan belajar yang sudah tersedia dan belajar merupakan suatu kegiatan yang bersifat prosedural. Lingkungan belajar demokratis menekankan kontrol proaktif siswa atas proses belajarnya sendiri, yang mencakup penetapan tujuan belajar sendiri, kontrol siswa terhadap urutan-urutan pembelajaran, hakekat pengalaman dan kedalaman materi belajar yang dicarinya. Sedangkan lingkungan belajar 
sibernetik menekankan saling ketergantungan antara sistem belajar dan siswa. (Schwier, 1993).

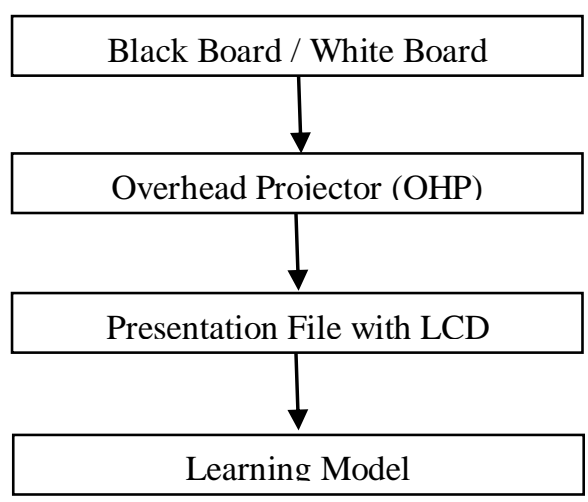

\section{Gambar 1. Evolusi Media Pembelajaran}

Beberapa penelitian yang telah dilakukan terhadap media pembelajaran yang statis dan media pembelajaran dalam bentuk multimedia menjelaskan bahwa dengan tampilan statis suatu gambar seharusnya menggambarkan fungsi pembelajaran, sasaran pembelajaran, dan materi yang dapat diimplementasikan yang dibutuhkan oleh pelajar, biasanya dalam text dokumen atau diagram. Sedangkan tampilan animasi untuk pembelajaran relatif lebih efektif karena lebih menarik, dan biasanya dalam bentuk aplikatif (Davidson, 2003).

Salah satu usaha yang dikembangkan mulai diarahkan kepada belajar kooperatif dalam pembelajaran multimedia (Klien \& Pridemore, 1992). Hooper (1992) memperluas pendekatan belajar kooperatif ini dalam lingkungan belajar yang berbasis komputer. Ia mengemukakan beberapa keuntungan dan penerapan belajar kooperatif dalam pembelajaran multimedia antara lain : 1) adanya ketergantungan dan tanggung jawab dari setiap anggota kelompok. 2) Adanya interaksi yang promotif di mana usaha seorang individu akan mendukung usaha anggota kelompok lainnya. 3) Kesempatan latihan untuk bekerjasama. 4) Pengembangan dan pemeliharaan kelompok. Proses kelompok yang terjadi di dalam lingkungan belajar ini bisa mendorong anggota kelompok untuk merefleksikan efektif atau tidaknya strategi yang digunakan. 


\section{Media Pembelajaran}

Media pembelajaran diartikan sebagai media yang membawa pesanpesan atau informasi yang mempunyai tujuan instruksional atau mengandung maksud pengajaran (Azhar Arsyad, 2003). Media pembelajaran meliputi alat yang secara fisik digunakan untuk menyampaikan isi materi pengajaran, yang terdiri antara lain buku, tape recorder, televisi, komputer, dan lainnya. Banyaknya media pembelajaran tersebut disesuaikan dengan tingkat kebutuhan dari pengguna. Karena tingkat keefektifan tergantung dari tujuan yang ingin dicapai.

Di era informasi seperti sekarang ini maka pilihan yang tepat atas media yang digunakan akan sangat menentukan proses dan hasil yang di didapatkan. Perlu adanya suatu kriteria didalam pemilihan media, diantaranya:

a. Sesuai dengan tujuan yang ingin dicapai.

b. Tepat untuk mendukung isi pelajaran.

c. Praktis, luwes, dan bertahan.

\section{Pembelajaran Berbasis Visual}

Media berbasis visual (image atau perumpamaan) memegang peranan yang sangat penting dalam proses belajar. Media visual dapat memperlancar pemahaman (misalnya melalui elaborasi struktur dan organisasi) dan memperkuat ingatan. Visual dapat pula menumbuhkan minat siswa dan dapat memberikan hubungan antara isi materi pelajaran dengan dunia nyata. Agar menjadi efektif, visual sebaiknya ditempatkan pada konteks yang bermakna dan siswa harus berinteraksi dengan visual (image) itu untuk meyakinkan terjadinya proses informasi.

Bentuk visual bisa berupa (a) gambar representasi seperti gambar, lukisan atau foto yang menunjukkan bagaimana tampaknya sesuatu benda; (b) diagram yang melukiskan hubungan-hubungan konsep, organisasi, dan struktur isi materi; (c) peta yang menunjukkan hubungan-hubungan ruang antara unsur-unsur dalam isi materi; (d) grafik seperti tabel, grafik, dan chart (bagan) yang menyajikan gambaran/ kecenderungan data atau antar hubungan seperangkat gambar atau angka- angka. 


\section{Pembelajaran Berbasis Audio-Visual}

Teknologi audio - visual merupakan cara menghasilkan atau menyampaikan materi dengan menggunakan mesin-mesin mekanis- elektronik untuk menyajikan pesan-pesan audio dan visual. Pembelajaran melalui audiovisual jelas bercirikan pemakaian perangkat keras selama proses belajar, seperti mesin proyektor film, tape recorder, dan proyektor visual yang lebar. Jadi, pembelajaran melalui audio-visual adalah produksi dan penggunaan materi yang penyerapannya melalui pandangan dan pendengaran serta tidak seluruhnya tergantung pada pemahaman kata atau simbol-simbol yang serupa.

\section{PembelajaranBerbasis Multimedia}

Pembelajaran dengan multimedia merupakan gabungan dari berbagai macam media yang terintegrasi yang secara bersama-sama menampilkan informasi, pesan, atau isi pelajaran.

Konsep penggabungan ini dengan sendirinya memerlukan beberapa jenis peralatan perangkat keras yang masing-masing tetap menjalankan fungsi utamanya sebagaimana biasanya, dan komputer merupakan pengendali seluruh peralatan itu. Jenis peralatan itu adalah komputer, video kamera, video casette recorder (VCR), overhead projector, multivision (atau sejenisnya), CD player, campact disc. CD Player yang sebelumnya merupakan peralatan tambahan (exsternal peripheral) komputer, sekarang sudah menjadi bagian unit komputer tertentu. Kesemua peralatan itu haruslah kompak dan bekerja sama dengan menyampaikan informasi kepada pemakainya.

Informasi yang disampaikan melalui multimedia ini berbentuk dokumen yang hidup, dapat dilihat dilayar ketika diproyeksikan melalui overhead projector, dan dapat didengar suaranya, dilihat gerakannya (video atau animasi). Multimedia bertujuan untuk menyajikan informasi dalam bentuk yang menyenangkan, menarik, mudah dimengerti, dan jelas. Informasi akan mudah dimengerti karena sebanyak mungkin indera, terutama telinga dan mata, digunakan untuk menyerap informasi itu. 
Bentuk informasi grafis, video, animasi, diagram, suara, dan lain-lain dengan mudah dapat dihasilkan dengan mutu yang cukup baik. Misalnya, video kamera berfungsi merekam video yang diinginkan kemudian ditransfer dan digabungkan dengan animasi, grafik, dan teks yang dihasilkan oleh komputer. Teks, grafik, animasi, video, sudah banyak tersedia dalam compact disc. Misalnya, Encyclopedia Americana sudah direkam kedalam compact disc, yang apabila ditampilkan didalam komputer melalui CD drive komputer itu maka informasi yang ada dalam disc baik berupa teks, gambar grafik, dan lain-lain dapat diakses dan dipindahkan untuk digabung dengan informasi lainnya.

\section{Multimedia}

\section{Pengertian Multimedia}

Dalam Kamus Amerika didefinisikan bahwa multimedia adalah kombinasi dari penggunaan beberapa media seperti film, slide, musik, penerangan dengan text, image, khususnya untuk tujuan pendidikan, dan hiburan. Unsur-unsur seperti teks, audio (narasi, dialog, sound effect), musik, film, video, fotografi, animasi dan grafik merupakan media pendukung yang tergantung dan terintegrasi menjadi satu-kesatuan karya multimedia. Bentuk Interaktif Multimedia termasuk didalamnya WebSite, CDRom Interactive, Program / software, Presentasi, Tutorial, Help section, dan bahkan Games.

\section{Elemen-elemen Multimedia}

Seperti yang telah diuraikan pada sub bab sebelumnya, multimedia merupakan sebuah penggabungan beberapa elemen-elemen ke dalam sebuah media, elemen-elemen yang digabungkan tersebut antara lain :

a. Teks, teks merupakan salah satu elemen terpenting dalam multimedia, dengan penggunaan teks penyampaian informasi akan lebih mudah dimengerti oleh pamakai. Teks biasanya merupakan informasi utama pada sebagian besar program multimedia. 
b. Gambar, gambar dapat berupa hasil dari foto, gambar yang telah diedit dan scanning. Berdasarkan cara pembuatannya, format file gambar dapat dibagi menjadi dua, yaitu:

1. Bitmap, bitmap yaitu sebuah gambar yang terdiri dari kumpulan bit pada memori komputer yang mendefinisikan warna dan intensitas setiap pixel dari gambar.

2. Vector, vector yaitu sebuah gambar yang disimpan dalam bentuk sekumpulan instruksi geometris

c. Suara (Audio), Suara yang dihasilkan dalam multimedia berisikan informasi suara yang kompleks, informasi tersebut antara lain :

- Berupa suara orang berbicara

- Musik, berupa suara yang dihasilkan untuk alat musik baik akustik maupun elektrik.

- Efek suara (sound effect) adalah suara selain percakapan dan musik, seperti suara gelas pecah, halilintar dan lain- lain.

Suara terdiri dari berbagai format file, antara lain:

1. WAV (Waveform), merupakan format audio digital yang disimpan secara digital. File ini disimpan dalam bentuk extension *.WAV. (Yuswanto, 2003)

2. MIDI (Music Instrument Digital Interface), merupakan protokol yang menghubungkan informasi yang bersifat musik antara lain musik dan soundcard. File-file MIDI disimpan dengan ekstensi *.MID dengan menggunakan soundcard sebagai MIDI device. File MIDI tidak memuat data bentuk suara apapun, yang ada dalam sebuah file MIDI adalah informasi digital yang memerintahkan alat MIDI. (Yuswanto, 2003)

3. Animasi, merupakan gambar yang bergerak dan dihasilkan dari pemasangan frame-frame gambar secara tepat yang untuk menghasilkan efek pergerakan, sehingga tampil seperti hidup. Animasi ini dapat dibagi menjadi 2 bagian, antara lain:

1. Computer Based Animation, animasi dihasilkan oleh komputer untuk membuat suatu visual efek yang meliputi perubahan posisi, bentuk, warna, struktur tekstur dari suatu objek. 
2. Full Motion Video, merupakan hasil rekaman dari kamera video yang berubah menjadi gambar hidup.

4. Video, merupakan sebuah animasi grafis yang mengambil objek secara langsung melalui video dan disimpan dalam dalam bentuk file audio dan video.

\section{PEMBAHASAN}

\section{Mendesain Web pada Photoshop}

1. Buka aplikasi photoshop. Mendesain dengan menggunakan Photoshop CS6.

2. Klik file > New, pilih Web pada preset. Pilih size sesuai ukuran kalian atau sesuai gambar berikut.

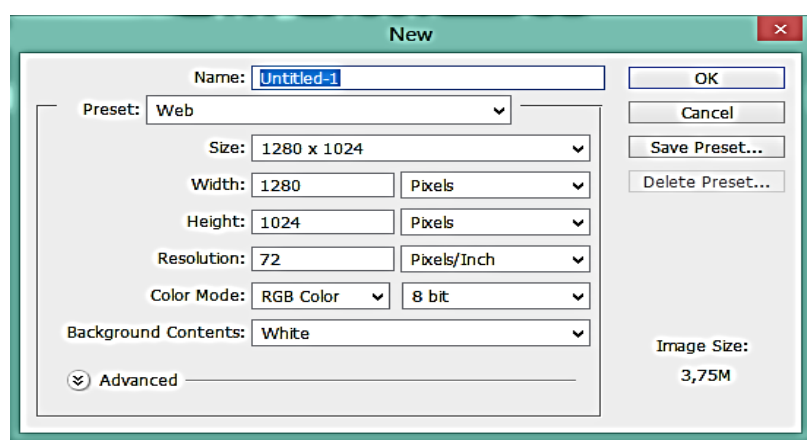

Gambar 2. Mengatur ukuran kanvas

3. Lalu akan muncul tampilan seperti berikut.

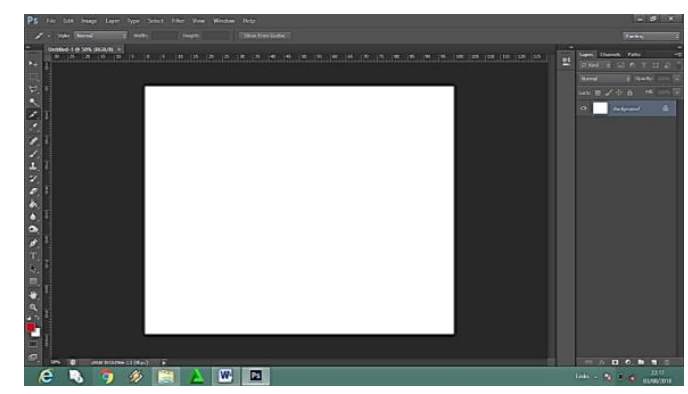

Gambar 3. Tampilan kanvas

4. Buatlah folder header dengan cara klik create a new group.

5. Lalu desain sesuai dengan imajinasi dan kreativitas anda.

6. Ulangi langkah 4 dan 5 untuk membuat folder footer. 
7. Kalau desain sudah selesai dikerjakan, kemudian desain anda potong Ipotong menggunakan slice tool agar menjadi layout pada web.

8. Berikut ini contoh desain yang sudah di slice.

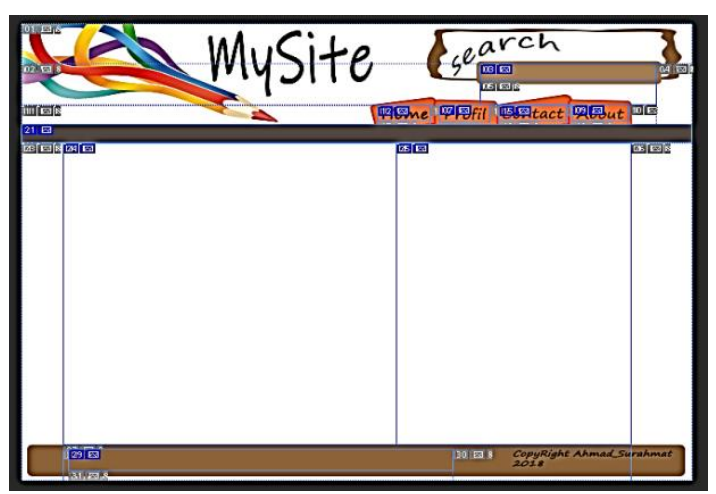

Gambar 4. Layout desain yang sudah di slice tool

9. Lalu klik file > safe for web.

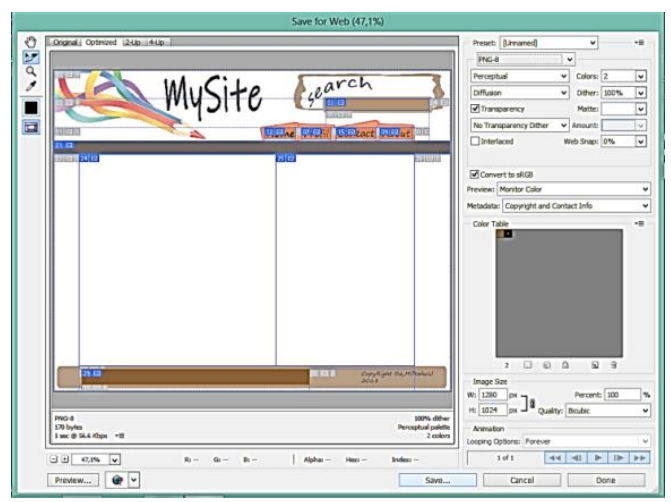

Gambar 5. Menyimpan hasil desain web

10. Tentukan tempat penyimpanan. Isikan nama dan pilih format $H T M L$ and images, klik save, dan akan didapatkan file dalam bentuk HTML dan folder images.

\section{Menambahkan Code dengan Adobe Dreamweaver}

Setelah anda mendapatkan file HTML, selanjutnya akan kita tambahkan code dengan adobe dreamweaver untuk tombol navigasi, tulisan bergerak, video, dan music supaya tampilan desain web menjadi lebih sempurna.

1. Buka hasil HTML yang sudah dibuat dengan Photoshop menggunakan aplikasi Adobe Dreamweaver. 
2. Klik Split untuk memudahkan kita menambahkan code.

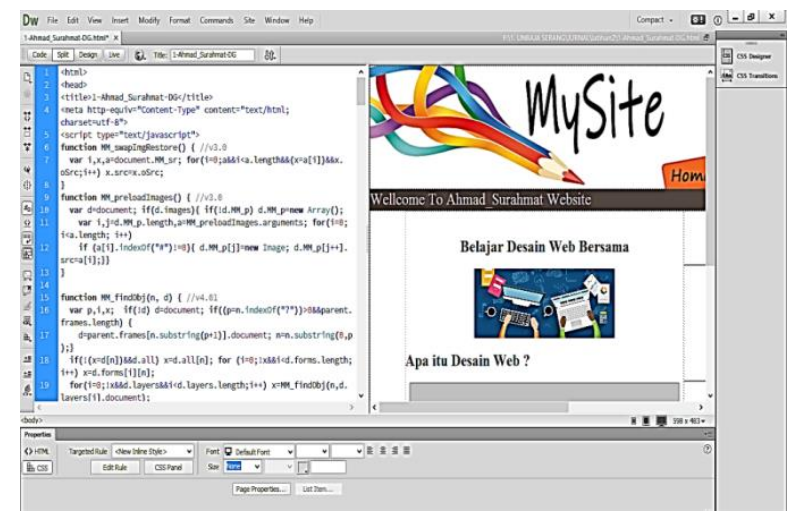

Gambar 6. Menambahkan code dengan split

3. Setelah anda selesai menambahkan code, klik Prieview in Google Chrome (F12) lalu klik Save untuk melihat hasilnya.

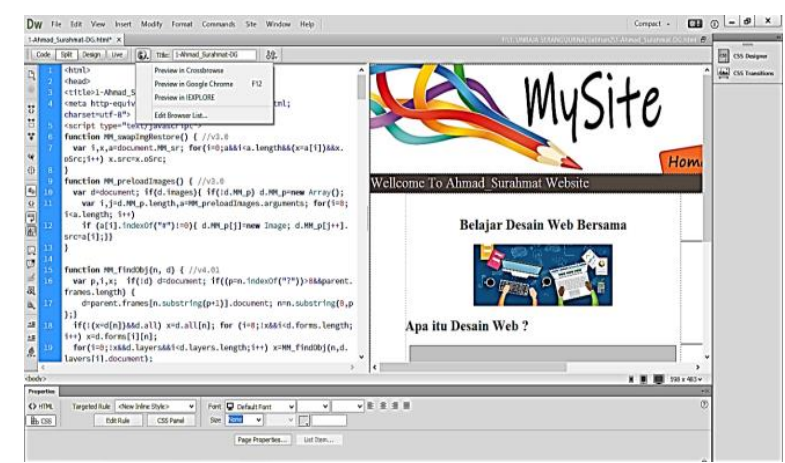

Gambar 7. Melihat hasil melalui Google Chrome

4. Berikut ini hasilnya.

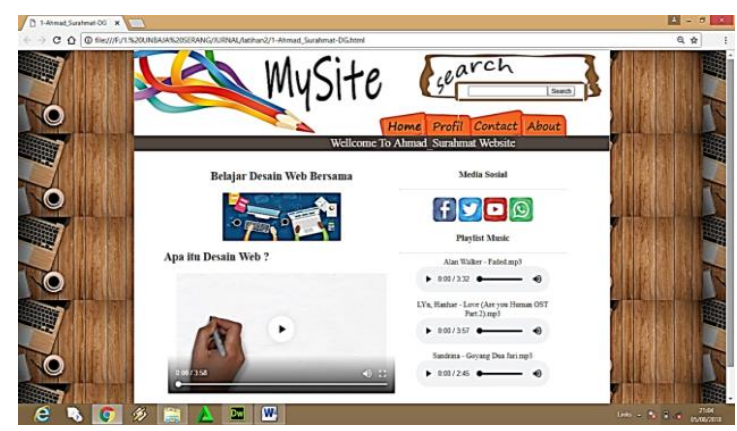

Gambar 8. Layout desain web secara offline 


\section{Membuat video pembelajaran menggunakan Camtasia Studio}

\section{Langkah membuat rekaman}

1. Buka Camtasia. Ketika pertama kali memulai Camtasia, Anda akan dibawa ke jendela Editor. Di sinilah semua fitur program Camtasia dapat ditemukan. Anda akan menggunakan Editor

2. untuk mulai merekam dan kemudian membersihkannya setelah selesai.

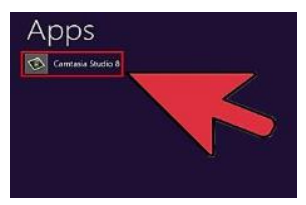

\section{Gambar 9. Aplikasi Camtasia studio}

3. Klik tombol "Record the screen". Tombol ini terletak di sudut kiri atas jendela Camtasia. Mengeklik tombol akan otomatis meminimalkan jendela Camtasia Editor dan membuka panel kontrol untuk merekam layar.

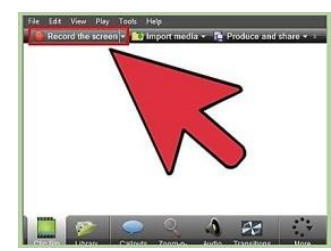

\section{Gambar 10. Tombol untuk merekam}

4. Pilihlah area perekaman. Jika Anda akan beralih antara beberapa jendela, Anda akan merasa lebih mudah untuk merekam seluruh layar. Rekaman Full Screen diaktifkan secara baku.

- Anda dapat membuat area perekaman yang memiliki ukuran, dengan cara mengeklik tombol Custom.

- Sebuah garis putus-putus akan muncul di sekitar area yang akan disimpan.

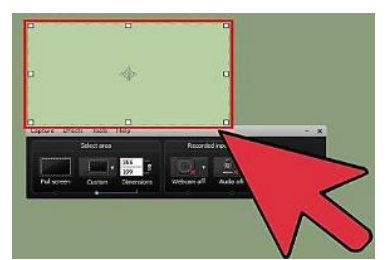

Gambar 11. Area perekaman 
5. Pilih masukan audio dan video. Jika Anda ingin menggunakan kamera web, aktifkan dengan mengeklik tombol Webcam. Jika Anda memiliki beberapa mikrofon yang terhubung ke komputer, klik panah bawah disamping tombol "Audio" untuk memilih salah satu mikrofon yang akan digunakan. Gunakan menu Audio untuk beralih atau menonaktifkan sistem suara. Jika Anda memilih status On, sistem sinyal dan bunyi bip akan terekam di presentasi Anda.

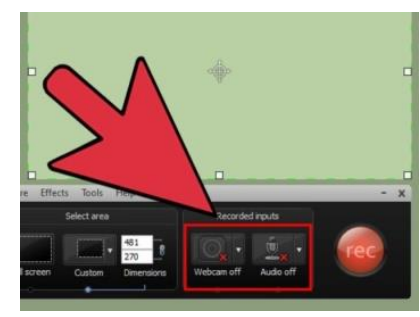

\section{Gambar 12. Penggunaan audio dan video}

6. Ujilah masukan audio. Jika Anda menggunakan mikrofon, ujilah sebelum merekam untuk melihat level yang muncul di bawah panel geser volume. Sesuaikan panel geser volume sampai masukan berada di sekitar pertengahan panel geser.

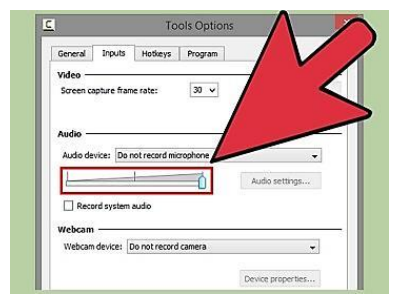

\section{Gambar 13. Pengaturan volume}

7. Bukalah jendela yang dibutuhkan. Sebelum mulai merekam, buka semua jendela yang harus Anda buka selama presentasi. Ini akan mencegah Anda dari meraba-raba jendela yang Anda butuhkan.

8. Mulailah merekam. Ambil napas dalam-dalam, dan tekan tombol REC atau tombol pintas F9. Sebuah hitung mundur akan muncul di layar. Setelah menghilang, semua yang Anda lakukan di layar dan semua yang Anda katakan akan direkam. 
9. Akhiri rekaman. Setelah selesai dengan presentasi, tekan F10 untuk menghentikan perekaman. Anda juga dapat menghentikannya dari bilah tugas, namun tindakan ini akan direkam dan harus diedit.

- Setelah selesai merekam, pratinjau presentasi yang direkam akan muncul.

Saksikan pratinjau tersebut untuk memastikan semuanya terlihat bagus, kemudian tekan tombol "Save and Edit".

- Berikan nama yang mudah diingat untuk proyek Anda. Anda dapat membuat folder baru jika Anda ingin membagi proyek ini menjadi beberapa berkas.

\section{Langkah mengedit rekaman}

1. Buka proyek tersebut di Editor Camtasia. Jika Anda baru saja selesai merekam dan menonton pratinjau, proyek secara otomatis akan dibuka di Editor. Di sinilah Anda akan membuat perubahan, memotong bagian yang tidak diperlukan dan menambahkan transisi.

2. Pilihlah dimensi video. Sebelum Anda dapat mengedit, Anda akan ditanyakan dimensi untuk video hasil akhirnya. Anda dapat memilih berbagai prasetel dari menu tarik-turun. Prasetel ini memiliki tulisan tujuan penggunaannya masing-masing.

- Gunakan salah satu dimensi otomatis. Dimensi ini didasarkan dari dimensi rekaman awal, dan ukurannya diubah untuk menjaga proporsi. Memilih salah satu dari ini akan membantu mencegah gambar terlihat tidak bagus.

- Anda dapat mengubah dimensi editing setiap saat dengan mengeklik tombol Dimensions di bagian atas jendela pratinjau.

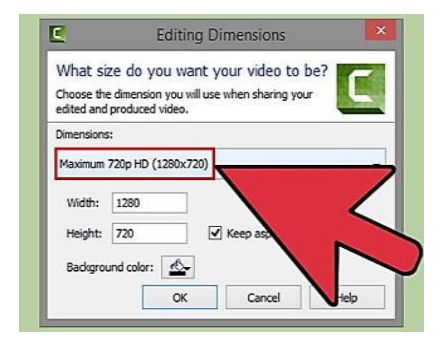

Gambar 14. Mengatur dimensi video 
3. Buanglah audio dan video yang tidak diinginkan. Selalu ada beberapa kesalahan di dalam presentasi. Untungnya, Anda dapat menghapus kesalahan tersebut dengan cepat, hanya dengan beberapa klik. Catatan: Jika audio dan video berada pada trek terpisah pada lini waktu, menghapus bagian yang satu tidak akan menghapus bagian yang lain.

- Gunakan alat navigasi lini waktu untuk menemukan titik potong yang tepat. Klik kaca pembesar untuk memperbesar lini waktu, untuk kontrol yang lebih tepat.

- Klik dan tarik tab merah di bagian atas alat navigasi Timeline. Tarik tab merah ke ujung bagian yang ingin dipotong.

- Tekan Space untuk memutar hanya bagian yang dipilih.

- Klik tombol Cut (ikon gunting) di atas Timeline untuk menghapus seleksi.

4. Periksa apakah SmartFocus sudah diterapkan dengan benar. Jika Anda memperkecil dimensi video, Camtasia akan menerapkan efek SmartFocus untuk memperbesar dan menggeser presentasi agar fokus pada elemen aktif, dan menempatkan fokus pada kursor dan jendela aktif.

- Anda dapat melihat di mana SmartFocus otomatis ditambahkan dengan mencari ikon di Timeline.

- Klik dan tarik ikon SmartFocus untuk bergerak saat transisi terjadi.

- Klik ikon SmartFocus lalu klik tombol Properties Visual untuk mengedit persis bagaimana transisi terjadi. Anda dapat membuat penggeser lebih lambat atau lebih cepat, memperbesar atau memperkecil zum, atau menghapus transisi SmartFocus seluruhnya.

- Anda dapat menghapus semua animasi SmartFocus dengan mengeklik kanan pada salah satu ikon dan memilih "Delete all visual animations on media".

5. Tambahkan seranta pada presentasi. Seranta adalah alat bantu visual yang membantu menarik perhatian pengunjung pada aspek-aspek penting presentasi. Seranta dapat berupa teks atau simbol atau sorotan. Anda juga dapat menggunakan seranta untuk mengaburkan bagian layar. 
- Gunakan Timeline untuk menavigasi ke bagian presentasi yang ingin Anda tambahkan seranta.

- Klik tombol Callout di atas Timeline.

- Buatlah seranta. Anda dapat menggunakan berbagai bentuk pradesain, mengetik teks sendiri, atau memilih seranta animasi.

- $\quad$ Klik tombol "+Add callout" untuk menambahkannya ke presentasi.

- Pindahkan seranta ke sekitar presentasi dengan menariknya di sekitar jendela pratinjau. Anda dapat menyesuaikan panjang seranta dari Timeline.

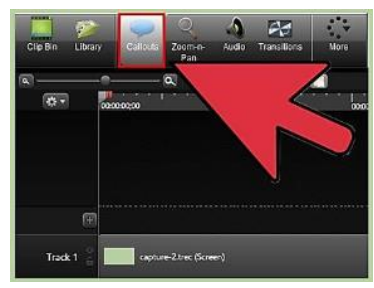

\section{Gambar 15. Penggunaan seranta}

\section{Menerbitkan dan berbagi rekaman}

1. Klik tombol "Produce and share". Setelah video diedit dan siap untuk dilihat, saatnya untuk mengekspor dan membaginya. Klik tombol "Produce and share" untuk memulai.

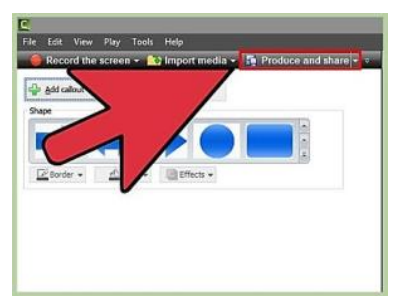

\section{Gambar 16. Tombol mengekspor video}

2. Pilih tujuan berbagi. Anda dapat berbagi langsung ke layanan yang telah ditentukan, seperti Screencast.com dan YouTube. Anda juga dapat membuat berkas video untuk membaginya sendiri atau mengunggahnya ke layanan lain. Ketika membuat berkas video, pilih opsi "MP4 Only". Ini akan membuat video tersebut dapat diputar pada hampir perangkat apa pun.

3. Masuklah ke layanan berbagi Anda. Jika Anda mengunggah ke YouTube atau Screencast, Anda akan dimintai informasi masuk sehingga Camtasia 
dapat terhubung ke layanan tersebut dan mengunggah video dengan akun Anda.

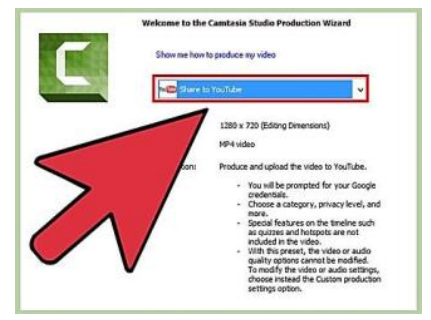

\section{Gambar 17. Membagi video ke Youtube}

4. Gunakan setelan produksi khusus. Jika Anda harus membuat video dalam format selain yang telah disediakan, klik pilihan "Custom production settings" ketika menyelesaikan video. Anda dapat memilih berbagai format yang ada, termasuk WMV, MOV, AVI, dan bahkan GIF.

- MP4 adalah format yang paling universal untuk perangkat dan web pengaliran.

- Hati-hati ketika memilih resolusi produk akhir Anda. Meningkatkan resolusi akan menghasilkan penurunan kualitas. Sebagai contoh, jika Anda merekam dalam resolusi $800 \times 450$, hindari penerbitan dalam resolusi 1920x1080.

- Seimbangkan antara ukuran dan kualitas. Ketika mengatur pilihan video, Anda akan melihat panel geser "Smaller file" di sebelah kiri dan "Higher quality" di sebelah kanan. Memindahkan panel geser akan berpengaruh terhadap kualitas akhir video. Jagalah ukuran berkas jika Anda akan mendistribusikan video ke banyak orang.

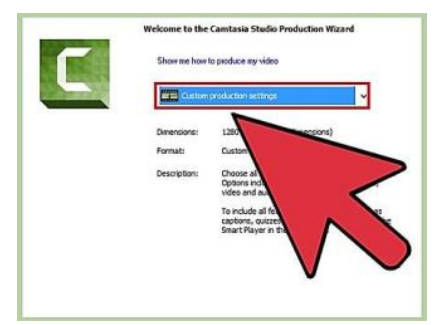

\section{Gambar 18. Tombol pilihan menyelesaikan video}

5. Putuskan antara video saja atau mengemasnya dengan program pemutar. Camtasia dapat menghasilkan video yang dibuka dengan bilah 
pengontrol Camtasia. Meskipun Anda tidak dapat mengunggahnya ke layanan video pengaliran, Anda dapat menggunakannya di situs Anda sendiri atau mendistribusikannya melalui cara lain.

\section{HASIL}

Penelitian ini dilakukan untuk mengembangkan media pembelajaran sehingga dapat meningkatkan mutu pendidikan di sekolah maupun di Perguruan Tinggi. Penelitian ini berlangsung dalam empat tahapan yaitu pembuatan template untuk desain web, menambahkan tampilan desain web, perekaman video dan pembuatan video.

Tahap pertama dengan Adobe Photoshop bagaimana cara membuat desain web dengan template yang sudah ada, dengan langkah - langkah yang sudah diberikan. Tahapan dalam pembuatan desain web adalah menyiapkan template yang menarik, membuat design, dan menyimpan hasil design dalam bentuk HTML.

Tahap kedua menambahkan tampilan desain web dengan menyisipkan music, video dan tulisan yang bergerak menggunakan bantuan Adobe Dreamweaver. Agar hasil dari desain web tadi menjadi menarik dan hidup.

Tahap ketiga menggunakan aplikasi Camtasia Studio merupakan tahapan perekaman video yang digunakan untuk media pembelajaran. Tahapan dalam perekaman video adalah

1. Membuka aplikasi Photoshop CS6

2. Membuka Adobe Dreamweaver

3. Mengaktifkan Sound Recorder

4. Mengaktifkan Camera Recorder

5. Merekam

Tahap keempat merupakan tahap terakhir dimana kegiatan yang telah direkam tadi dibuat video untuk media pembelajaran dalam bentuk seperti $C D$, DVD, Ipod dan HD. Selain itu video yang dihasilkan dapat dikirim ke Youtube, Web dan Internet. 


\section{KESIMPULAN}

1) Penggunaan aplikasi Photoshop selain untuk desain grafis, seperti editing foto, iklan, lukisan dan icon. Dapat juga untuk membuat tampilan desain web dengan mudah dan cepat.

2) Menambahkan tampilan desain web berupa music, video dan tulisan bergerak dengan menggunakan Adobe Dreamweaver.

3) Aplikasi Camtasia Studio untuk pengembangan media pembelajaran berupa video pembelajaran.

4) Video pembelajaran yang dihasilkan dapat dilihat dengan format .wav .flv .swf. Dengan kualitas CD, DVD.

\section{DAFTAR PUSTAKA}

A.Taufiq Hidayatullah. Cara Mudah Modifikasi Foto Digital Menggunakan Photoshop CS6 dan Photo Effects Studio. Buana Pustaka. Yogyakarta. 2013

Azhar Arsyad. Media Pembelajaran. PT. Raja Grafindo Persada. Jakarta. 2003

Davidson. Web based learning: designing, implementation, and evaluation. Upper Saddle River, NJ: Pearson Education, Inc. 2003

Dharna A. Ilustrasi Digital dan Teknik Profesional Photoshop. Universitas Atma Jaya Yogyakarta

Fundamental of camtasia studio, TechSmith Corporation, 2010

http://im-informatika.blogspot.com/2014/12/cara-desain-web-simpel-danmudah.html

http://www.burung-net.com/2015/03/pengertian-dan-fungsi-adobedreamweaver.html

https://jery21tik.blogspot.com/2015/05/pengertian-dan-penggunaancamtasya.html

Klein, J. D., \& Pridemore, D. R. Effects of individual versus cooperative learning and type of reward on performance and continuing motivation. Contemporary Educational Psychology. 1992

Richard A. Schwier dan Earl R. Misanchuk. Interactive Multimedia Instruction, New Jersey : Educational Technology Publications. 1993

Widodo, C. Buku Panduan Menyusun Bahan Ajar. PT. Elex Media Komputindo. Jakarta. 2008 